University of Wollongong

Research Online

Faculty of Law, Humanities and the Arts Papers (Archive)

Faculty of Arts, Social Sciences \& Humanities

$1-1-2017$

Combatting counterfeit drugs: Case studies of Cambodia, Vietnam and Thailand

Jakkrit Kuanpoth

Tilleke and Gibbins International Ltd, jakkrit@uow.edu.au

Follow this and additional works at: https://ro.uow.edu.au/lhapapers

Part of the Arts and Humanities Commons, and the Law Commons

Research Online is the open access institutional repository for the University of Wollongong. For further information contact the UOW Library: research-pubs@uow.edu.au 


\title{
Combatting counterfeit drugs: Case studies of Cambodia, Vietnam and Thailand
}

\author{
Abstract \\ Medicines can save lives only if they are safe, efficacious, of good quality and affordable. The use of \\ unsafe, substandard, ineffective and counterfeit drugs can be harmful to the health of the users and the \\ public. Governments have an obligation to ensure the safety, efficacy and quality of the drugs available to \\ the public by regulating the manufacturing and distribution of drugs and by exercising legal power to \\ control the proliferation of unsafe counterfeit medicines. This article surveys the factual and legal issues \\ surrounding counterfeit drugs in three countries, namely Cambodia, Vietnam and Thailand, in order to \\ determine the magnitude and characteristics of the drug counterfeiting problem within the Southeast \\ Asian region. \\ Keywords \\ drugs:, studies, counterfeit, cambodia, combatting, vietnam, thailand, case \\ Disciplines \\ Arts and Humanities | Law \\ Publication Details \\ J. Kuanpoth, 'Combatting counterfeit drugs: Case studies of Cambodia, Vietnam and Thailand' (2017) 13 \\ Journal of Generic Medicines: The Business Journal for the Generic Medicines Sector 1-16.
}




\begin{abstract}
Medicines can save lives only if they are safe, efficacious, of good quality and affordable. The use of unsafe, substandard, ineffective and counterfeit drugs can be harmful to the health of the users and the public. Governments have an obligation to ensure the safety, efficacy and quality of the drugs available to the public by regulating the manufacturing and distribution of drugs and by exercising legal power to control the proliferation of unsafe counterfeit medicines. This article surveys the factual and legal issues surrounding counterfeit drugs in three countries, namely Cambodia, Vietnam and Thailand, in order to determine the magnitude and characteristics of the drug counterfeiting problem within the Southeast Asian region.
\end{abstract}

Keywords:

counterfeit drugs; substandard drugs; Vietnam, Cambodia, Thailand 


\section{Combatting Counterfeit Drugs:}

\section{Case Studies of Cambodia, Vietnam, and Thailand}

Jakkrit Kuanpoth $^{*}$

\section{Introduction}

The people's right to health includes the right of access to a reliable standard of healthcare and a good quality drug product. Medicines can save lives only if they are safe, efficacious, of good quality and affordable. The use of unsafe, substandard, ineffective and counterfeit drugs can be harmful to the health of the users and the public. Governments have an obligation to ensure the safety, efficacy and quality of the drugs available to the public, which can be done by: (1) regulating the manufacture, export, import, storage, distribution, supply and sale of drugs, and (2) exercising legal power to control the proliferation of unsafe counterfeit medicines. The prevalence of drug counterfeiting in Southeast Asian countries, including Cambodia, Laos, Myanmar, Thailand and Vietnam is evident, which poses a public health risk, contributes to poor treatment outcomes and wastes precious public and private financial resources in those countries. The drug counterfeiting problem in those countries is occurring with great frequency due to the substantial profits that can be realised from such transactions. The increase in counterfeiting may also be motivated by other factors, including the economic incentives provided by an increasing volume of high cost drugs, ineffective drug regulation, weakness of law enforcement and the ability to manufacture, transfer and distribute drugs from one country to another. ${ }^{1}$ This

\footnotetext{
* Of Counsel of Tilleke and Gibbins International Ltd; Visiting Professorial Fellow at the University of Wollongong
} 
article surveys the factual and legal issues surrounding counterfeit drugs in three Southeast Asian countries, namely Cambodia, Vietnam and Thailand, in order to determine the magnitude and characteristics of the drug counterfeiting problem within the region. Part 1 examines the extent of the problems in the countries surveyed. Part 2 discusses existing laws of Cambodia, Vietnam and Thailand that regulate the distribution and marketing of medicines. This legal analysis will examine whether or not the current legal framework of the three countries is adequate and effective in dealing with counterfeit drugs. Part 3 examines the concept and definition of counterfeit drugs in order to avoid variations in the legal interpretation and implementation. The issues of law enforcement and border controls are surveyed in Parts 4 and 5 in order to detect the problems of combatting counterfeit drugs in the three countries.

\section{Extent of drug counterfeiting problems in Cambodia, Vietnam and Thailand}

Drug counterfeiting is an illegal activity, which is hard to detect and investigate. It is hard to know or even estimate the true extent of the problem. What is known is that it occurs in almost all countries and is more prevalent in developing countries. Available information illustrates the extent and seriousness of the problem, which persists despite national and regional efforts to tackle it. According to the World Health Organization (WHO), it is estimated that about 10 percent of the drugs available worldwide may be counterfeit. ${ }^{2}$ According to the World Customs Organization (WCO), the value of counterfeit drugs is estimated to be USD 200 billion per year. The WCO reported that in 2013 alone more than half of 24,092 cases of seizures of intellectual property infringing goods were related to illegal medicines. ${ }^{3}$ It was found that over 920 medical products from all the main therapeutic categories, including medicines, vaccines and in vitro diagnostics, have been found to be counterfeit drugs. ${ }^{4}$ While counterfeit drugs have been 
reported in all regions of the world, the prevalence of drug counterfeiting in various countries throughout Southeast Asia appears to be rising. The counterfeit drugs that have been found in the region include antibiotics, anti-malarial agents, anti-tubercular drugs, anti-retroviral agents, vitamins, painkillers, hormones, and steroids. ${ }^{5}$ Particularly, the quantities of available fake artesunate, a drug for the treatment of multi-drug resistant Plasmodium falciparum malaria, are strikingly high in the region and were found in Cambodia, Laos, Myanmar, Thailand and Vietnam. According the 2001 survey, among 104 shop-bought samples taken from those five countries, 30 samples (29\%) was found to contain no artesunate and 39 samples (38\%) were counterfeit. ${ }^{6}$ A more recent study has shown similar results. ${ }^{7}$ Because of the high prevalence of counterfeits, it is believed that Asia is the region most frequently linked to pharmaceutical crime incidents, including drug counterfeiting. ${ }^{8}$

Cambodia, one of the three countries studied, shares borders with Thailand, Laos, and Vietnam. Cambodia is, in fact, not a major producer of counterfeit drugs, but it suffers badly from counterfeit and illicit medicines due to the rapid increase in recent years in the production of counterfeit drugs in other Asian countries. The proliferation of counterfeit drugs in the country can be attributable to the economic incentives provided by the increasing volumes of high cost drugs, ineffective drug regulations, weaknesses of local law enforcement, the ability to import drugs into vulnerable countries and corruption. ${ }^{9}$ A study undertaken by Rozendal on fake antimalarial drugs in Cambodia found that patients and village heath providers preferred counterfeit drugs because their prices were lower. ${ }^{10}$

As we can observe in similar patterns across Southeast Asia, the counterfeiting of drugs in Cambodia usually appears in the form of finished pharmaceuticals, i.e. the final product taken by 
the patient, rather than the counterfeiting of bulk drug ingredients. This is due to the country's lack of manufacturing capacity. Currently, there are only six (6) drug manufacturers throughout Cambodia. Counterfeit drugs are usually not produced in Cambodia but are illegally imported into the country. ${ }^{11}$ However, Cambodian Customs officials believe that a small number of counterfeit drug products may be produced locally. During my field work in Cambodia, I had discussions with the Cambodian authorities. They told me that they are becoming increasingly concerned with the significant increase in the amounts of counterfeit drugs coming into the country from China, India, Thailand, Vietnam and elsewhere in the region. Though the drug officials are fully aware that most counterfeit drugs come from abroad, the challenges of protecting against unsafe counterfeit drugs is difficult as there are several channels through which drugs can be brought into the country. The lack of investigation and prosecution in the countries where counterfeit drugs are produced makes it almost impossible to stop the importation of drugs into Cambodia. Additionally, although the Cambodian Government and its drug agency, i.e. the Department of Drug and Food (DDF), have recently adopted an integrated plan for enforcing prohibitions against counterfeit drugs, the challenges still remain, including a lack of financial and human resources, inadequate supplies of safe medicines and outdated regulatory systems, resulting in many counterfeit drugs escaping detection until they reach the retail consumer level.

In Cambodia, criminal activities related to drug counterfeiting have become an increasing problem with many illegal drug outlets operating and selling drugs without licences from the DDF. Drug outlets and pharmacy shops are the country's most important distribution channels. The drug outlets, many of which are wholesalers, purchase drug products directly from manufacturers and importers and then sell those products directly to consumers. The number of 
illegal drug outlets is larger than the outlets licensed by the DDF. While there are 1,014 regulated drug outlets consisting of 393 pharmacies, 175 depot A, and 446 depot B, the number of illegal outlets is estimated to be 2,461. Both licensed and unlicensed drug outlets and pharmacy shops may knowingly or unknowingly distribute counterfeit drugs. However, the drug official I interviewed believed that the volume of counterfeits sold by illegal outlets was much higher than that supplied through the licensed outlets. The official also agrees that Cambodia needs tougher regulations against illegal drug distributors.

In Vietnam, the number of counterfeit drugs is quite high. According to a survey undertaken by the National Institute of Drug Quality Control of Vietnam, 7 percent of the 25,000 samples collected from 20 provinces were found to be counterfeit. ${ }^{12}$ The counterfeit drugs, particularly anti-malaria drugs, are prevalent in Vietnam. For example, 64 percent of artesunate drugs bought in the country were found to be counterfeit. ${ }^{13}$ A report of the EU-Vietnam Business Network (EVBN) confirms that Vietnam's pharmaceutical market suffers from the proliferation of counterfeit drugs and a lack of certified pharmacies and pharmacists. ${ }^{14}$

Counterfeiting of medicines is also a growing problem in Thailand. Although there are no collected data on drug counterfeiting, counterfeit medications have been found in the Thai market from time to time. The drug authority has discovered counterfeiting activities involving both production and smuggling. It was reported that 11 percent of artesunate drugs taken from shops in Thailand were found to be counterfeit. ${ }^{15}$ In 1989 , a licensed manufacturer was found to be producing unregistered antibiotics with little active ingredients. In 1998, the drug authority, in collaboration with the police, arrested an unauthorised manufacturer who was illegally producing counterfeit drugs. In 2001, two companies selling counterfeit Viagra medication were arrested 
and subsequently prosecuted. In 2002, a drug store in Bangkok was charged for selling counterfeit drugs. In 2003, a person who was smuggling fake Viagra into Thailand was arrested at the airport. ${ }^{16}$ An investigation in 2015 by Al Jazeera showed that fake medicines are openly being sold on the streets in Thailand. ${ }^{17}$

A counterfeit drug has better capacity to deceive, particularly if it is copied to make it look like the original product. Samples of counterfeit drugs collected by the drug regulatory authorities in Cambodia, Vietnam and Thailand show substantive similarities to the genuine products. Drug inspectors in those countries admitted to me that it was difficult for them to detect whether a product is counterfeit. This would be far more difficult for patients to detect whether the product they are buying is of good quality. The prevalence of counterfeit drugs is due to the fact that such drugs are easy to carry. The lack of investigation and prosecution in the countries where the counterfeit drugs are produced makes it almost impossible to stop the smuggling and importing of drugs from other countries. Cambodia and Vietnam have set up an inter-ministerial committee on this issue, and Cambodia has adopted an integrated plan against the importation and distribution of counterfeit drugs and has actively implemented it over the past few years. From January 2009 to October 2011, the Cambodian Ministry of Health, in collaboration with the WHO, initiated a project to contain and examine artemisinin-resistant Plasmodium falciparum malaria. ${ }^{18}$ The inter-ministerial committee on counterfeit drugs started a campaign against illegal drug outlets, reducing the number in Cambodia from 1,420 in 2009 to 87 in $2010 .{ }^{19}$

\section{Legislation combating counterfeit drugs in Cambodia, Vietnam and Thailand}


As in most countries, counterfeit drugs in the countries studied (i.e. Cambodia, Vietnam and Thailand) pose potentially serious public health and safety concerns. However, there is no specific law enacted to deal with this problem in any of the three countries. The control of drug counterfeiting in these countries is under the national drug laws discussed below.

\section{Cambodian law}

As in most countries, counterfeit drugs in Cambodia pose potentially serious public health and safety concerns, but no specific legislation has been passed to combat this threat. The regulation of pharmaceuticals in Cambodia is under the national drug law called the "Management of Pharmaceuticals Act (MPA)", which was enacted in 1996 and was subsequently amended in 2007. The MPA comprises 15 articles, providing controls on manufacturing, the importation of medicines, inspections, and law enforcement. The Act has the main aim of ensuring that pharmaceutical products distributed in Cambodia are safe and effective and seeks to avoid an unacceptable risk of counterfeit, adulterated, misbranded, substandard or expired drugs being sold to the public.

The main articles used by law enforcement bodies are summarised below.

1) The DDF is authorised to issue Sub-decrees and Prakas (i.e. notifications) to regulate the distribution and production of pharmaceuticals. The DDF can issue a license for the establishment of a drug manufacturer, and for the importing, exporting, selling and advertisement of drugs. All drug outlets are required to have a pharmacist or a health professional who has acquired the appropriate certificate from the Ministry of Health (MOH) (Articles 7 and 8). 
2) Any person who (1) engages in any production, importation, exportation, advertising or distribution of drugs without authorisation from $\mathrm{MOH}$, (2) violates the procedures and conditions for the production, importation, exportation and selling of drugs, and (3) changes the location of the approved establishment without authorisation from the $\mathrm{MOH}$, shall be subject to a fine of KHR 1 million (Cambodian riel) and a suspension of such activities for a period of one to three months in the discretion of the drug regulatory authority (Article 10).

3) Any person who deliberately engages in producing, importing, exporting or distributing (1) drugs containing addictive substances without authorisation, (2) counterfeit and substandard drugs, or (3) expired drugs that affect the health or lives of the consumers, shall be deemed guilty of a criminal offence and on conviction thereof, shall be punished by a fine ranging from KHR 20 million to 50 million, or by imprisonment between five and ten years, or by both said punishments, in the discretion of the court (Section 12).

However, the MPA seems to be ineffective against counterfeiting practices. It does not contain any safeguard measures to deal with the importation of counterfeit drugs. Since drugs sold in Cambodia are manufactured outside its borders, the lack of effective enforcement to combat the importation of the counterfeit drugs that are flooded the Cambodian market is of major concern. Certain mechanisms to help address some of the risks posed by counterfeit drugs must be introduced. This includes increasing the criminal penalties for distribution of unapproved or misbranded drugs. The law could also improve the regulatory process for imported drugs and authorise the authorities to administratively detain imported drugs suspected to be counterfeit. A clear definition of counterfeit drugs that is in line with the WHO definition must also be adopted. 
Vietnamese law

In Vietnam, pharmaceutical legislation and regulation is in the form of a series of complementary laws. Like its neighbours, Vietnam has no specific law dealing with the problem of counterfeit drugs. The control of drug counterfeiting in Vietnam is under various laws, including the following:

- Criminal Act

- Law on the People's Health Protection

- Law on Prevention of Public Health

- Ordinance on Private Medical and Pharmaceutical Practices

- Decree on Drugs for Prevention and Treatment of Human

- Various regulations, including the Regulation on Management of Drug Quality, the Regulation on Drug Sampling, and the Regulation on Drug Registration

The laws of Vietnam include provisions relating to manufacturing, importing, distribution, marketing, labelling, dispensing, inspecting and law enforcement. This legislation and the accompanying regulations have the identical aim of ensuring the quality and efficacy of the pharmaceutical products sold to the public, and prohibiting counterfeit, adulterated, misbranded, substandard, or expired drugs being sold to the public. For example, Article 29 of the Ordinance on Private Medical and Pharmaceutical Practices prohibits individuals and legal entities from selling counterfeit drugs. Article 157 of the Criminal Act provides criminal sanctions for those dealing in counterfeit drugs. According to the provision, the criminal penalties for the offences of producing, importing, exporting and distributing counterfeit drugs are two to seven years imprisonment and a fine of between VND 5 million and 50 million (Vietnamese dong). The law 
also authorises the drug regulatory authority to impose a suspension or revocation of the practising licence of a health professional found producing or selling counterfeit drugs for a period ranging from one to five years.

One of the regulatory authorities, the Drug Administration of Vietnam (DAV) under the Ministry of Health, was established for administrative control. The DAV is authorised to regulate the distribution and production of pharmaceuticals. It can issue a licence to run pharmaceutical manufacturing establishment, or issue a licence to import, export, sell or advertise drugs. All drug distributors and pharmacies are required to retain a pharmacist or a health professional who has acquired the appropriate certificate from the authorities.

Under Vietnamese law, a drug retailing establishment, which is entitled to distribute drugs, must obtain a good pharmacy practice (GPP) certificate from the Department of Health. The certificate can only be issued to those who meet the required conditions regarding personnel and infrastructure set out by the Health Department. The legal consequences for non-compliance will result in the cancellation of the certificate and a fine ranging from VND 500,000 to VND 40 million. Under the law, the $\mathrm{MOH}$ is responsible for supervising distribution activities. Also, drug establishments must be randomly inspected on a regular basis. However, I was told during my interviews that licensed establishments are rarely inspected due to the MOH's lack of qualified inspectors. This inadequacy is a major contributing factor to the prevalence of unauthorised distributors and unregistered products in Vietnam.

The drugs that are distributed in Vietnam must have marketing authorisation, which is issued by the DAV, with some exceptions for drugs intended to be used for special purposes. Although the relevant law of Vietnam contains provisions dealing with drug counterfeiting, there is still 
weakness in the existing law. First, it provides weak penalties for drug counterfeiting, which are simply not sufficient to deter the criminal element in the counterfeit drug trade. The penalty for dealing with counterfeit drugs is two to seven years' imprisonment, and then only if the authorities are able to show that the offender has a specific intent to produce or distribute the counterfeit drugs. In addition, Vietnamese law does not impose severe penalties for unlicensed distributors or street vendors, which are generally the major channels of counterfeit drug distribution. It also does not impose criminal charges against representatives of companies or juristic persons who are involved in counterfeiting, thus allowing counterfeiters to escape detection, arrest, and penal sanctions. Further, the law does not provide guidelines and checklists to guide regulatory practice in handling counterfeit drugs.

Thai law

In Thailand the control of counterfeit drugs is under the Drug Act B.E. 2510. The regulation of drugs in Thailand is administered by the Food and Drug Administration (FDA) of the Ministry of Public Health. The distribution and importation of medicines requires an import and/or manufacturing licence, which can be issued by the FDA. In addition, drugs to be distributed in Thailand must also be registered with the Thai FDA. There are some exceptions under which certain drugs do not require product registration. For example, a doctor may distribute medicines directly to his or her patients without a licence. The Notification of the Ministry of Public No. 14, B.E. 2532, states that certain medicines imported into Thailand may be exempted from product registration if they are used for research, analysis, exhibition or charitable purposes. However, the right to import drugs without a licence is limited to certain agencies, including to a government agency with duties encompassing the prevention and treatment of diseases, the Thai 
Red Cross Society, and the Government Pharmaceutical Organisation. Any person who commits a violation of the regulations is subject to administrative (i.e. cancellation of licence) and criminal sanctions (i.e. imprisonment and fines).

Under the Drug Act B.E. 2510, the criminal penalties for the offences of producing, importing, exporting, and distributing counterfeit drugs are three years to life imprisonment and a THB 10,000 to 50,000 (Thai baht) fine for producing counterfeit drugs, and a jail term of one to twenty years and a THB 2,000 to 10,000 fine for selling, importing or ordering counterfeit drugs. The law also provides for the suspension or revocation of the practising licence of those found producing or selling counterfeit drugs. The Drug Act B.E. 2510 provides criminal sanctions against distributing unregistered drugs. The sanction for this offence, according to Thai law, is three years' imprisonment and a THB 5,000 fine.

Comparatively, the main features of the pharmaceutical laws of the three countries are similar, which can be summarised as follows:

- The laws of the three countries provide controls on manufacturing, importation, inspections and law enforcement. This legislation and the complementary regulations have the identical aim of ensuring that pharmaceutical products in the country are safe and effective and avoiding an unacceptable risk of counterfeit, adulterated, misbranded, substandard or expired drugs being sold to the public.

- In those countries, the drug regulatory authorities are authorised to regulate the distribution and production of pharmaceuticals. They can issue a licence for establishing a drug manufacturer, importing, exporting, selling and advertising drugs. All drug distributors and pharmacies are required to retain a pharmacist or 
a health professional who has acquired the appropriate certificate from the authorities.

- The laws of the three countries provide administrative and criminal sanctions for those dealing in counterfeit drugs. The criminal penalties for the offences of producing, importing, exporting and distributing counterfeit drugs include: (1) in Cambodia a fine from KHR 20 million to 50 million or imprisonment between five and 10 ten years; (2) in Vietnam two to seven years' imprisonment; and (3) in Thailand three years to life imprisonment and a THB 10,000 to 50,000 fine for producing counterfeit drugs, in addition to a jail term of one to twenty years and a THB 2,000 to 10,000 fine for selling, importing or ordering counterfeit drugs. The laws of the three countries also provide for the suspension or revocation of the practising licence of those found producing or selling counterfeit drugs.

- The laws of Cambodia and Thailand provide criminal sanctions against the distribution of unregistered drugs, but the penalties for this offence are not severe enough. For example, those who produce and sell unregistered drugs are subject to a fine of KHR 10 million and one to three months imprisonment under Cambodian law. The sanctions for the same offence, according to Thai law, are three years' imprisonment and a THB 5,000 fine. No criminal sanctions are imposed on the person who produces and sells unregistered drugs under Vietnamese law.

Although the relevant laws of Cambodia, Vietnam and Thailand contain provisions dealing with drug counterfeiting, there is still weakness in the existing law. For example, it provides weak 
penalties for drug counterfeiting, particularly in the cases of Cambodia and Vietnam. In addition, the laws of the three countries do not impose severe penalties for unlicensed distributors, which are generally the major channels of counterfeit drug distribution. They also do not impose criminal charges against representatives of companies or juristic persons, which allows counterfeiters to escape detection, arrest and penal sanctions. The laws of the three countries do not provide guidelines or checklists to guide regulatory practice in handling counterfeit drugs. The inadequacy of the laws and regulations leads to the prevalence of unauthorised distributors and unregistered products. The respective governments may need to enact special national legislation on counterfeit drugs in order to improve the regulatory process and to stiffen penalties for those who engage in counterfeiting.

\section{Definition of counterfeit drugs}

Counterfeit drugs are defined differently in different countries. The absence of a universally accepted definition makes collaboration between countries very difficult. Differentiation of the definition of counterfeit drugs under the laws of different countries can lead to variations in the

legal interpretation and implementation to combat or prevent drug counterfeiting. To implement effective countermeasures against counterfeit drugs, a unified definition under the laws of each of the affected countries is required. The World Health Organization (WHO) has formulated such a definition as follows:

"A medicine, which is deliberately and fraudulently mislabelled with respect to identity and/or source. Counterfeiting can apply to both branded and generic products and counterfeit products may include products with the correct ingredients or with the wrong 
ingredients, without active ingredients, with insufficient active ingredients or with fake packaging." 20

The WHO definition refers to counterfeit drugs as those produced with an intention to mislabel a product. The WHO definition also differentiates counterfeit drugs from substandard drugs. Substandard drugs are genuine medicinal products that do not meet quality specifications set for them by national standards. ${ }^{21}$ The term 'substandard' is used to describe the quality status of genuine drugs produced by legitimate manufacturers. Normally, for each medicinal product that a manufacturer produces it must meet the quality standards or specifications set by national drug authorities. If a drug, upon laboratory testing in accordance with the specifications with which it claims to comply, fails to meet such specifications, then it is classified as a substandard drug.

Cambodian law

Clause 1 of the Official Notification on the Prohibition for Selling Counterfeit Drugs 2003, which was enacted to implement the MPA, divides counterfeit drugs into four categories: (1) drugs that are deliberately produced with no or insufficient active ingredients; (2) drugs that are deliberately produced with incorrect active ingredients, according to defined pharmacopoeias standards; (3) drugs that are deliberately and fraudulently mislabelled with respect to identity or source; and (4) drugs that are repacked, produced or imported without a licence.

Vietnamese law

The Decree on Drugs for Prevention and Treatment of Humans defines counterfeit drugs as "products deliberately and fraudulently manufactured without or with very low content of active 
ingredients, containing incorrect ingredients, or with packaging similar to the drugs of other producers." Vietnam's definition is in line with that of the WHO's definition.

Thai law

Section 73 of the Drug Act B.E. 2510 defines counterfeit drugs as "(1) a drug or substance that is wholly or partly an imitation of a genuine drug; (2) a drug that shows the name of another drug, or an expiry date that is false; (3) a drug that shows a name or mark of a producer, or the false location of the producer; (4) a drug that falsely shows that it is in accordance with a formula that has been registered; and (5) a drug produced with active substances for which the quantity or strength is lower than the minimum or higher than the maximum standards prescribed in the registered formula by more than twenty percent." This definition is obviously different from the WHO's definition, as it provides a wider definition of counterfeit drugs, covering substandard drugs. Substandard drugs, i.e. drugs produced with active substances for which the quantity or strength is lower than the minimum or higher than the maximum standards prescribed in the registered formula by more than twenty percent, are regarded as counterfeit drugs under Thai law.

The following provides examples and a comparison of counterfeit pharmaceutical products, according to the WHO definition and the laws of the three countries: ${ }^{22}$

\begin{tabular}{|l|l|l|l|l|}
\hline \multicolumn{1}{|c|}{ Drugs } & WHO & Cambodia & Vietnam & Thailand \\
\hline fake packaging + correct quantity of & counterfeit & counterfeit & counterfeit & counterfeit \\
correct ingredients & & & & \\
\hline
\end{tabular}




\begin{tabular}{|c|c|c|c|c|}
\hline fake packaging + wrong ingredients & counterfeit & counterfeit & counterfeit & counterfeit \\
\hline $\begin{array}{l}\text { fake packaging }+ \text { no active } \\
\text { ingredients }\end{array}$ & counterfeit & counterfeit & counterfeit & counterfeit \\
\hline $\begin{array}{l}\text { fake packaging }+ \text { incorrect quantity } \\
\text { of correct ingredients }\end{array}$ & counterfeit & counterfeit & counterfeit & counterfeit \\
\hline $\begin{array}{l}\text { genuine packaging }+ \text { wrong } \\
\text { ingredients (deliberate) }\end{array}$ & counterfeit & counterfeit & counterfeit & $\begin{array}{l}\text { counterfeit, if } \\
\text { quantity or } \\
\text { strength of } \\
\text { ingredients is } \\
20 \% \text { higher or } \\
\text { lower than the } \\
\text { registered } \\
\text { formula }\end{array}$ \\
\hline $\begin{array}{l}\text { genuine packaging }+ \text { no ingredients } \\
\text { (deliberate) }\end{array}$ & counterfeit & counterfeit & counterfeit & counterfeit \\
\hline $\begin{array}{l}\text { genuine packaging }+ \text { incorrect } \\
\text { quantity of ingredients (deliberate) }\end{array}$ & counterfeit & counterfeit & counterfeit & $\begin{array}{l}\text { counterfeit, if } \\
\text { quantity or } \\
\text { strength of } \\
\text { ingredients is } \\
20 \% \text { higher or } \\
\text { lower than the } \\
\text { registered } \\
\text { formula }\end{array}$ \\
\hline $\begin{array}{l}\text { genuine packaging }+ \text { incorrect } \\
\text { quantity of ingredients (not }\end{array}$ & substandard & substandard & substandard & $\begin{array}{l}\text { counterfeit, if } \\
\text { quantity or }\end{array}$ \\
\hline
\end{tabular}




\begin{tabular}{|l|l|l|l|l|}
\hline deliberate) & & & & strength of \\
ingredients is \\
$20 \%$ higher or \\
lower than the \\
registered \\
formula
\end{tabular}

While Vietnam's definition is in line with that of the WHO definition, the Cambodian and Thai legislation provides a different definition for counterfeit drugs. The definition under Cambodian law, unlike that of the WHO definition, regards unregistered drugs as counterfeit drugs. Thai law provides a wider definition covering substandard drugs (i.e. drugs produced with active substances for which the quantity or strength is lower than the minimum or higher than the maximum standards prescribed in the registered formula by more than twenty percent).

\section{Law implementation and enforcement}

Counterfeiting is generally difficult to detect, investigate and quantify. However, it is especially difficult to know the true extent of the problem, due to the lack of investigative efforts and recorded figures. It is widely believed that drug counterfeiting is widespread and has generated severe adverse effects on the health and livelihoods of the people in the three countries under 
discussion. The high prevalence of counterfeit drugs in this region can be mainly contributable to (1) absence of or weak anti-counterfeiting laws; and (2) weak or insufficient law enforcement.

Cambodia

The only way the counterfeiting problem in Cambodia can be solved is to strengthen the drug regulatory authority. This in turn needs strong government resolve and commitment to provide adequate human, financial and other resources, appropriate infrastructure and legal power to enforce drug regulation. Unfortunately, like many other developing countries, the existence of drug counterfeiting in Cambodia does not seem to draw much oversight from the government. The authority to bring alleged violators of pharmaceutical law and regulations to court resides in the DDF. The DDF derives its authority from the MPA and is given the power to enforce the law. As is the case with most Cambodian government entities, the DDF suffers badly from organizational shortcomings. A senior Cambodian government official told me that he wanted to combat trafficking and distribution. However, several factors constrain any sustained advance in effective law enforcement, including a lack of requisite funding and adequate resources to support the law enforcement mission, an acute shortage of trained personnel, lack of basic training in law enforcement techniques and drug law enforcement measures, high levels of official corruption, and lack of collaboration between law enforcement bodies.

Regarding the licenced drug outlets, the DDF has sole authority to implement the drug law. It can grant cease and desist orders, and penalties for violations of cease and desist orders, if it finds that any licenced drug outlets have violated the law, including the selling of counterfeit drugs. However, such authority has not been taken seriously. Though the law stipulates that the licence of a drug outlet found to be violating the law shall be suspended for one to three months, 
the suspended drug outlets can request for a pardon from the $\mathrm{MOH}$. In practice, once a request for a pardon is submitted to the $\mathrm{MOH}$, the pardon is granted almost automatically. This partly explains why the measure aimed at regulating drug outlets is ineffective to help combat the counterfeiting problem.

The DDF has exclusive authority over the enforcement of the law against any authorised outlets found violating drug laws and shares authority with other regulatory agencies, including municipality authorities and the Ministry of Interior, for enforcing the law against those outlets operating without a licence. However, the DDF has no power to collect the evidence and information necessary for their enforcement of the drug law against the illegal outlets. Cooperation with the police, the local authority and the judiciary is required to bring criminal charges against those operating without a license. A criminal action can be initiated by the drug regulatory authority, but a raid at an illegal drug outlet can only be carried out in the presence of representatives of the four law enforcement agencies, i.e. the $\mathrm{MOH}$, the National Police Bureau, the municipality and the court. A successful raid will lead to the arrest of the offender and seizure of the counterfeit drugs. The offender is then prosecuted in the court.

Cooperation between different authorities to close down all illegal drug outlets, which are the major suppliers of counterfeit drugs, suffers from significant gaps in drug law enforcement. Procedural obstacles exist between such enforcement authorities. As a result, there have been few court cases relating to drug law. I was informed that in the past ten years 32 operators of illegal outlets were arrested and prosecuted. Only half of those were convicted, and the same number of outlets received court orders to close down. No doubt, the relatively small number of illegal drug outlets closed down had virtually no effect on the scope of the problem. 
The unsuccessful litigation against the illegal outlets can be explained by the fact that the courts did not accept evidence submitted by the regulatory authority, claiming that such evidence had been wrongfully obtained. In addition, there is a high burden of proof on the drug authority in criminal proceedings. It has to be shown that the defendant is guilty beyond reasonable doubt. This high burden of proof is especially difficult to overcome when trying to prove that the defendant knew, or had reason to believe, that he was selling counterfeit drugs. Attempts have been made by government bodies to cooperate in investigations, inspections and acquisition of evidence. The $\mathrm{MOH}$ is currently considering proposing setting up of an inter-ministerial committee concerning counterfeit drugs, which should lay the groundwork for judicial and law enforcement cooperation among different authorities. Since cooperation between the DDF, the police, Customs, and the judiciary is rather weak, it seems necessary that inter-sectoral cooperation between regulatory authorities must be urgently undertaken for effective control of the national drug market and enforcement of drug legislation. When such cooperation is delayed or ineffective, counterfeiters will continue to escape detection, arrest and penal sanctions.

Vietnam

While interviewing a Vietnamese official, I was informed that the Government has taken serious action against drug counterfeiting. It has introduced several measures to ensure the safety, efficacy and quality of the medicines available to the public, including the promulgation of the Law on Protection of People's Health in 1989, the adoption of the National Drug Policy in 1996, the setting up of the inter-ministerial committee on counterfeit drugs, and other courses of action. The new law on Pharmacy regulation was approved by the National Assembly of Vietnam on 4 June 2016, which will take effect in late 2017 and will improve the health care system of 
Vietnam. The government has also attempted to ensure that all 34,300 pharmacies operating in the country are licenced and regularly inspected. However, the officials admitted that attempts to implement and enforce the law have been constrained by several factors, including an acute shortage of trained personnel, lack of adequate resources and inspection capacity, and lack of collaboration between law enforcement bodies.

As in Cambodia and Thailand, the Vietnamese drug regulatory authority has exclusive power over the enforcement of the drug laws against any authorised pharmaceutical distributors found violating those laws. The Government established an inter-ministerial committee against counterfeit drugs, which laid the groundwork for judicial and law enforcement cooperation among different authorities. It is believed that the establishment of that committee has improved the enforcement of the law against counterfeit drugs and helped to reduce the current number of counterfeit drugs to 0.03 percent.

Thailand

Thailand considers the problem of drug counterfeiting a priority. A special task force to combat counterfeit drugs was established under the Drug Control Division of the FDA. However, the shortage of personnel is the major obstacle to implementing and enforcing the law against counterfeit drugs, especially in remote areas. Apart from the problems mentioned above, the three countries also share a common problem of their respective drug authorities' insufficient power to carry out inspections. Ineffective or weak drug inspections have promoted smuggling operations and the illegal distribution of drugs, which has led to the proliferation of counterfeit drugs on the national market. It seems necessary that the drug law be amended to give strong legal powers to drug inspectors to conduct inspections at all drug outlets, ports and airports. 
Routine sample inspections of imported drugs, including mandatory inspections, will have to be clearly delineated under the new law. Empowering the inspectors will have a strong impact on the legal and illegal drug markets, but the law must regard drug-inspection fraud as a criminal offence so that the government can take serious action against the wrongdoers. Like Cambodia and Vietnam, Thailand's drug authority is not presently equipped to carry out regular inspections. The enforcement of the drug law also requires collaboration between various agencies in order to bring criminal charges against manufacturers and distributors operating against the law. However, unlike Cambodia and Vietnam, the Thai government has no plans to establish an inter-ministerial committee against counterfeit drugs, as the Government does not consider the lack of collaboration problem to be an issue.

However, it may be suggested that inter-sectoral collaboration is essential in the battle against drug counterfeiting. Cooperation among not only regulatory authorities but also between the government and the private sectors is required and should be urgently undertaken for effective control of the national drug market and enforcement of drug legislation. Effective collaboration between government authorities, industry and non-governmental bodies would help to track counterfeit drugs and identify counterfeiters. In addition, cooperation in some matters with foreign counterparts can result in greater efficiency and consistency in law enforcement.

\section{Border controls}

Though the countries' regulatory authorities are fully aware that the majority of counterfeit drugs come from abroad, the challenge of protecting the public against unsafe counterfeit drugs is difficult because there are several channels through which drugs can be transported across the 
borders. Since the counterfeiting of drugs has now become a regional issue affecting all countries in the Southeast Asian region, an effective regional collaboration, similar to the one related to narcotic drugs, is desirable. The respective governments also need to tighten border controls to fight against the smuggling of counterfeit medicines.

\section{Cambodia}

Customs officers have power to inspect and seize counterfeit drugs at the borders. However, the country's main international airport, Pochentong, and its regional airport in Siem Reap, suffer from lax Customs and immigration controls. Customs controls in both airports are rudimentary. The Customs authority told me that random inspections are carried out to prove the validity of an importer's import licence, registration number and the expiry date of drugs, but so far, no illegal imported drugs have been seized and no smugglers have been arrested. The DDF used to have drug inspectors stationed at the airports and along key transit routes near Cambodia's borders with Vietnam and Thailand, but the crackdown at the borders was discontinued for two reasons: (1) lack of manpower, capacity and funding to inspect imported drugs at the borders, and (2) to support the government policy of promoting free trade with neighbouring countries. No doubt, the inefficiency of law enforcement at the borders has led to a flood of unauthorised drugs into Cambodia.

Ineffective or weak drug inspections have promoted smuggling and the illegal distribution of drugs, which has led to the proliferation of counterfeit drugs on national market. It seems necessary that the drug law be amended to give strong legal powers to drug inspectors to conduct 
inspections at all drug outlets, ports and airports. Routine sample inspections of imported drugs, including mandatory inspections, will have to be clearly delineated under the new law. Cambodia may wish to revive its border inspection policy for counterfeit drugs. Customs officers, together with drug inspectors, should be required to work closely together and to carry out reasonable surveillance on imported goods, including the authority to issue an order for seizure of drugs found to be counterfeit.

\section{Vietnam}

The DAV does not have its officials stationed at the borders. Customs has the sole authority to control the drugs imported into the country. In practice, Customs officials attempt to inspect all drugs imported into the country, but the inspection can only be carried out to ensure that the imported drugs comply with the import requirements, such as having a proper licence, registration number and correct specifications, as stipulated in the importation documents. There is no quality checking of the imported drugs at the borders but random quality testing is carried out at various warehouses. The officials admitted that the smuggling of counterfeit drugs is not easy to detect due to Vietnam's long borders with its neighbouring countries.

\section{Thailand}

Thailand allows pharmaceuticals to be imported into the country through certain checkpoints. There are five control points through which the importation of raw materials used for pharmaceutical purposes can be made. There are 24 control points through which the importation of finished products is allowed. Drugs imported through these transit routes are inspected by FDA and Customs officials. The FDA has recently conducted quality testing of 
imported drugs at Suvarnabhumi Airport. Counterfeit drugs have been found at those border checkpoints from time to time. For example, Customs authorities in Thailand seized $75 \mathrm{~kg}$ of diazepam trafficked in 2008, and in the same year, $192 \mathrm{~kg}$ of pharmaceutical preparations containing pseudoephedrine were seized at the airport. ${ }^{23}$

The three countries studied share the same problems in controlling counterfeit drugs at their borders. The main problem concerns the lack of manpower, capacity and funding to inspect imported drugs. The inefficiency of law enforcement at the borders has led to a flood of unauthorised drugs into these three countries. It may be suggested that all countries in the region should increase the frequency of their respective border inspections for counterfeit drugs. Customs officials and drug inspectors must work closely together and engage in the active exchange of information and intelligence regarding counterfeit drugs. They should be required to perform reasonable surveillance on imported medicinal goods and to issue an order to seize those drugs found to be counterfeit.

\section{Conclusion}

Counterfeiting of drugs poses potentially serious public health and safety concerns. It affects not only patients and innocent users but also the general public, and deserves more attention from all governments. The problem has now become a regional issue affecting almost every country in Southeast Asia. In order to solve the problem effectively, the following actions should be considered: 
(1) The national drug laws in the countries facing the counterfeit drug problem should be revised and the following should be incorporated into those revisions:

- The law should introduce a clear and wide-ranging definition of counterfeit drugs. The definition should include drugs prohibited by official orders, expired drugs, unregistered drugs, and drugs that do not reflect their actual efficacy (i.e. substandard drugs).

- The law should require the drug regulatory authorities to establish an extensive regulatory framework to ensure that counterfeit pharmaceuticals will not be imported and distributed in the market.

- The law should introduce safeguards into the drug importation and distribution system to provide assurances, through paper records, of the true source(s) and distribution history of a drug. The offender may be ordered to disclose to the regulatory authorities the names and addresses of his or her suppliers or customers.

- The law should strengthen the authority granted to drug inspectors to conduct inspections. The officials of the drug regulatory authorities, who are designated as law enforcers, should be able to file a motion with the court for a search warrant in order to conduct a thorough investigation. This will somewhat alleviate the delay and breach of secrecy in the search.

- The law should observe the potential deterrence and other effects of stiffer penalties on those found guilty of drug counterfeiting. The higher penalties are required as the current penalties for some offences are not severe enough, such as weak penalties for the operation of a pharmacy without a licence. 
- Where the criminal activities related to counterfeit drugs are committed by a legal entity, the law should presume that all the members and managing directors of the legal entity are accomplices to the offence and subject to the liability prescribed for such offence.

(2) Once the revised law is adopted, the drug authorities and other relevant agencies must be committed to implementing an aggressive enforcement strategy to combat counterfeit drugs. The absence of legislation and deterrent sanctions will continue to encourage counterfeiters since there is no fear of being apprehended and prosecuted.

(3) Drug production and distribution will have to be more aggressively managed.

(4) The drug regulatory authorities should be strengthened sufficiently to play the central coordinating role in order to initiate more effective measures against drug counterfeiting. Adequate manpower and funding must be provided to the drug authorities to inspect producers, importers and distributors at the rate required to maintain drug quality.

(5) Large-scale and long-term international aid, including capacity building assistance and law-enforcement aid, should be provided by the relevant international agencies to help countries curb the distribution and trafficking of counterfeit drugs.

(6) The governments of all countries should run public education campaigns to educate consumers about the steps they can take to minimise the risks associated with counterfeit drugs. It should also educate consumers about what to look for, and what to do, if they suspect they have received a counterfeit drug.

(7) Cooperation with private parties should be undertaken. It would be prudent to implement any strategic initiatives requiring the cooperation of manufacturers, 
distributors, and retailers to track drugs through the marketplace, identify counterfeit drugs, and notify the drug regulatory authorities of any suspected counterfeit drugs.

(8) Countries should improve coordination among their state agencies, including the drug regulatory authority, Customs, the municipality, the police, and the judiciary. The national drug regulatory authority and other law enforcement agencies should also engage in the exchange of information regarding counterfeit drugs. This collaboration should also be undertaken with other interested parties, including foreign drug authorities and international organisations, such as the WHO and Interpol.

\footnotetext{
${ }^{1}$ Wang PG and Wertheimer A (eds.). Counterfeit medicines: policy, economics and countermeasures: volume I. Hertfordshire: ILM Publications, 2012. See also Blackstone EA, Fuhr J and Pociask S. The health and economic effects of counterfeit drugs. American Health and Drug Benefits 2014; 7/4: 216-224.

${ }^{2}$ Gibson, L. Drug regulators study global treaty to tackle counterfeit drugs. British Medical Journal 2004: 328: 486.

${ }^{3}$ World Customs Organization. The Illicit trade report 2014. Report 2014.

${ }^{4}$ World Health Organization. Substandard, spurious, falsely labelled, falsified and counterfeit (SSFFC). Fact sheet 2016. http://www.who.int/mediacentre/factsheets/fs275/en/. Accessed on 17 May 2017.

${ }^{5}$ World Confederation for Physical Therapy. Background document on counterfeit medicines in Asia. Report 2011. http://www.wcpt.org/node/44404 Accessed on 17 May 2017.

${ }^{6}$ Paul Newman et al. Fake artesunate in Southeast Asia. Lancet 2001; 357: 1948-1950.

${ }^{7}$ Phanouvong $\mathrm{S}$ et al. The quality of antimalarial medicines in Western Cambodia: a case study along the ThaiCambodian border. Southeast Asian J Trop Med Public Health. 2013; 44:349-362.

${ }^{8}$ World Confederation for Physical Therapy, op.cit. note 6.

${ }^{9}$ Newton PN, Green MD, Fernandez FM. Impact of poor-quality medicines in the 'developing' world. Trends Pharmacological Sciences. 2010, 31: 99-101. See Przyswa E. Counterfeit medicines and criminal organizations. Report presented by the Institute of Research against Counterfeit Medicines 2013. Available at www.iracm.com/wpcontent/uploads/2014/02/Contrefacon-de-Medicaments-et-Organisations-Criminelles-EN.pdf. Accessed on 18 May 2017.

${ }^{10}$ Rozendaal JA. Fake antimalaria drugs in Cambodia. Lancet 2001; 357: 890.

${ }^{11}$ Krech LA et al. Cambodian Ministry of Health takes decisive actions in the fight against substandard and counterfeit Medicines. Tropical Medicine \& Surgery 2014; 2: 166.

12 Wondemagegnehu E. Counterfeit and substandard drugs in Myanmar and Viet Nam - report of a study carried out in cooperation with the governments of Myanmar and Viet Nam. Report, World Health Organization. 1999.

${ }^{13}$ Newman et al, op.cit. note 6, 1948.

${ }^{14}$ EU-Vietnam Business Network, Healthcare research report. Report 2015. Available at https://www.flandersinvestmentandtrade.com/export/sites/trade/files/news/223150528071429/223150528071429_1. pdf Accessed on 22 May 2017.

${ }^{15}$ Wondemagegnehu, op.cit. nnote 12.

${ }^{16}$ Interview with an official, Food and Drug Administration of Thailand, Nonthaburi, February 2016.

${ }^{17}$ Algazeera. Trade in harmful counterfeit pills going global. Report 2015. Available at http://www.aljazeera.com/indepth/features/2015/04/trade-harmful-counterfeit-pills-global-150407064627401.html Accessed on 22 may 2017.

${ }^{18}$ Krech, op.cit. note 12.
} 
19 Ibid.

${ }^{20}$ World Health Organization. General information on counterfeit medicines. Report 2015. Available at www.who.int/medicines/services/counterfeit/overview/en/ Accessed on 20 February 2017.

${ }^{21}$ Ravinetto R, Boelaert M, Jacobs J, Pouget C, Luyckx C. Poor-quality medical products: time to address substandards, not only counterfeits. Tropical Medicine \& International Health 2012; 17(11): 1412-6.

${ }^{22}$ Wondemagegnehu, op.cit note 13.

${ }^{23}$ INCB, Report of the International Narcotics Control Board for 2014. New York 2015. 